\title{
Codelivery of dihydroartemisinin and doxorubicin in mannosylated liposomes for drug-resistant colon cancer therapy
}

\author{
Xue-jia KANG ${ }^{1,2}$, Hui-yuan WANG ${ }^{2}$, Hui-ge PENG ${ }^{2}$, Bin-fan $\mathrm{CHEN}^{2}$, Wen-yuan ZHANG ${ }^{2}$, Ai-hua WU ${ }^{1,2}$, Qin XU ${ }^{1, *}$, Yong-zhuo \\ $\mathrm{HUANG}^{2, *}$ \\ ${ }^{1}$ Institute of Tropical Medicine, Guangzhou University of Chinese Medicine, Guangzhou 510405, China; ${ }^{2}$ Shanghai Institute of Materia \\ Medica, Chinese Academy of Sciences, Shanghai 201203, China
}

\begin{abstract}
Multidrug resistance (MDR) is a major hurdle in cancer chemotherapy and makes the treatment benefits unsustainable. Combination therapy is a commonly used method for overcoming MDR. In this study we investigated the anti-MDR effect of dihydroartemisinin (DHA), a derivative of artemisinin, in combination with doxorubicin (Dox) in drug-resistant human colon tumor HCT8/ADR cells. We developed a tumor-targeting codelivery system, in which the two drugs were co-encapsulated into the mannosylated liposomes (Manliposomes). The Man-liposomes had a mean diameter of $158.8 \mathrm{~nm}$ and zeta potential of $-15.8 \mathrm{mV}$. In the HCT8/ADR cells that overexpress the mannose receptors, the Man-liposomes altered the intracellular distribution of Dox, resulting in a high accumulation of Dox in the nuclei and thus displaying the highest cytotoxicity $\left(\mathrm{IC}_{50}=0.073 \mu \mathrm{g} / \mathrm{mL}\right)$ among all the groups. In a subcutaneous $\mathrm{HCT} 8 / \mathrm{ADR}$ tumor xenograft model, administration of the Man-liposomes resulted in a tumor inhibition rate of $88.59 \%$, compared to that of $47.46 \%$ or $70.54 \%$, respectively, for the treatment with free Dox or free Dox+DHA. The mechanisms underlying the anti-MDR effect of the Manliposomes involved preferential nuclear accumulation of the therapeutic agents, enhanced cancer cell apoptosis, downregulation of $\mathrm{Bcl}-\mathrm{xl}$, and the induction of autophagy.
\end{abstract}

Keywords: human colon cancer; multidrug resistance; doxorubicin; dihydroartemisinin; combination therapy; tumor-targeted delivery; mannosylated liposome; mannose receptor

Acta Pharmacologica Sinica (2017) 38: 885-896; doi: 10.1038/aps.2017.10; published online 8 May 2017

\section{Introduction}

Colorectal cancer (CRC) has become the fourth leading cause of cancer death worldwide, accounting for 700000 deaths in $2012^{[1]}$. In China alone, 159000 people died of CRC in 2012 ${ }^{[2]}$. The incidence has been rapidly increasing due to an increased life expectancy and a diet high in fat and low in fiber ${ }^{[3]}$. Chemotherapy is a major method of CRC management. However, multidrug resistance (MDR) is almost unavoidable in the late stages, and renders unproductive treatment outcomes ${ }^{[4]}$.

One of the most recognized mechanisms of MDR is the overexpression of P-glycoprotein (P-gp). High levels of P-gp expression have been found in a large variety of drug resistance colorectal cancer cells ${ }^{[5,6]}$. The active drug efflux mediated by P-gp leads to an insufficient drug intracellular concen-

\footnotetext{
*To whom correspondence should be addressed.

E-mail yzhuang@simm.ac.cn (Yong-zhuo HUANG); xuqin@gzucm.edu.cn (Qin XU)

Received 2016-12-06 Accepted 2017-01-16
}

tration to kill tumor cells. Nanotechnology has been widely investigated for use in the reversal of MDR based on the sizeexclusion effect (also known as the "too-large-to-be-pumpedout" phenomenon) and the altered intracellular distribution, eg, targeting organelles ${ }^{[7,8]}$.

Moreover, other mechanisms, such as defective apoptosis and DNA repair, also play important roles in $\mathrm{MDR}^{[9]}$. Therefore, combination therapy has become a common approach in clinical practice to address MDR issues ${ }^{[10]}$. Discovery of natural compounds to overcome MDR cancers has attracted much attention; in particular, active ingredients from Chinese medicine have been widely investigated for their effects on reversing $\mathrm{MDR}^{[11]}$. Their combination with conventional chemotherapeutics represents a promising strategy for anti-MDR cancer therapies.

We developed a tumor-targeted liposomal codelivery system for doxorubicin (Dox) and dihydroartemisinin (DHA). Artemisinin is isolated from the Chinese medicinal plant Artemisia annua, and DHA is a derivative that has better water 
solubility. DHA has already been approved for clinical use as an antimalarial drug, and its potential as an anticancer therapy has been well demonstrated in vitro and in vivo stud$\operatorname{ies}^{[12,13]}$. More importantly, in combination with chemotherapeutics, DHA yields synergetic effects ${ }^{[14]}$, and re-sensitizes drug-resistant tumor cells to chemotherapy ${ }^{[15]}$. We prepared the mannose-modified liposomes (Man-lip) co-encapsulating Dox and DHA (Figure 1). The mannose receptor (MR, CD206) plays important roles in endocytosis in colon cancer cells ${ }^{[16]}$. We found that the MR was overexpressed in the drugresistant human colon tumor cell line HCT8/ADR. Therefore, it was expected that the MR-targeting ligand would not only improve delivery to the tumor but also enhance intracellular delivery. The Man-lip system was evaluated in a drugresistant colon tumor xenograft mouse model.

\section{Materials and methods}

\section{Materials, cell line, and animals}

Soybean phosphatidylcholine (SPC), cholesterol, and DSPE$\mathrm{PEG}_{2000}$-Amine were purchased from Advanced Vehicle Technology Co, Ltd (Shanghai, China). An annexin V-FITC/PI apoptosis detection kit was purchased from Beyotime Institute Biotechnology (Shanghai, China). Gibco fetal bovine serum (FBS) and RPMI-1640 medium were purchased from Thermo Fisher Scientific (USA). LC3B rabbit mAb antibody and mannose receptor antibody were purchased from Cell Signaling Technology (Danvers, USA). a-D-mannopyranosylphenyl isothiocyanate (MPITC) was purchased from Chemsynlab Co, Ltd (Beijing, China). Other reagents were purchased from
Sinopharm Chemical Reagent Co, Ltd (Shanghai, China). Doxorubicin and dihydroartemisinin were provided by Meilun Biotechnology Co, Ltd (Dalian, China).

The Dox-resistant human colon cancer cell line, HCT8/ADR, was obtained from Jiangsu KeyGEN BioTech Co, Ltd (Nanjing, China). The cells were cultured in RPMI-1640 medium supplemented with $10 \%$ FBS. Female BALB/c nude mice (18-22 g) were purchased from Shanghai Laboratory Animal Center, Chinese Academy of Sciences.

\section{Preparation and characterization of liposomes Synthesis of DSPE-PEG ${ }_{2000}-M_{\text {Mannose }}$}

Mannose was conjugated to the DSPE-PEG ${ }_{2000}-\mathrm{NH}_{2}$ via a reaction between isothiocyanate and amine groups (Figure 2). Briefly, MPITC was dissolved in $100 \mu \mathrm{L}$ of DMSO, and DSPE$\mathrm{PEG}_{2000}-\mathrm{NH}_{2}$ was dissolved in $3 \mathrm{~mL}$ of $\mathrm{H}_{2} \mathrm{O}$. Then, the MPITC solution was slowly added to the DSPE-PEG2000- $\mathrm{NH}_{2}$ solution at a molar ratio of 2:1 and stirred at room temperature (RT) for $3 \mathrm{~h}$. The reaction mixture was dialyzed (MWCO 1000 Da) for $24 \mathrm{~h}$ to remove free MPITC, and the product, DSPE$\mathrm{PEG}_{2000}-$ Mannose, was confirmed by ${ }^{1} \mathrm{H}$ NMR spectroscopy.

\section{Preparation and characterization of liposomes}

The liposomes were prepared by the thin-film hydration technique. Lipids (SPC/Chol/DSPE-PEG ${ }_{2000}-M_{\text {Mnnose or SPC/ }}$ Chol/DSPE-PEG ${ }_{2000}$ ) at a molar ratio of 27:11:0.6 dissolved in chloroform, desalted Dox in methanol, and DHA in ethanol, were mixed together, and the ratio of Dox, DHA, and lipids was $0.02: 10$ and 1:10 $(w / w)$, respectively. The organic solvents

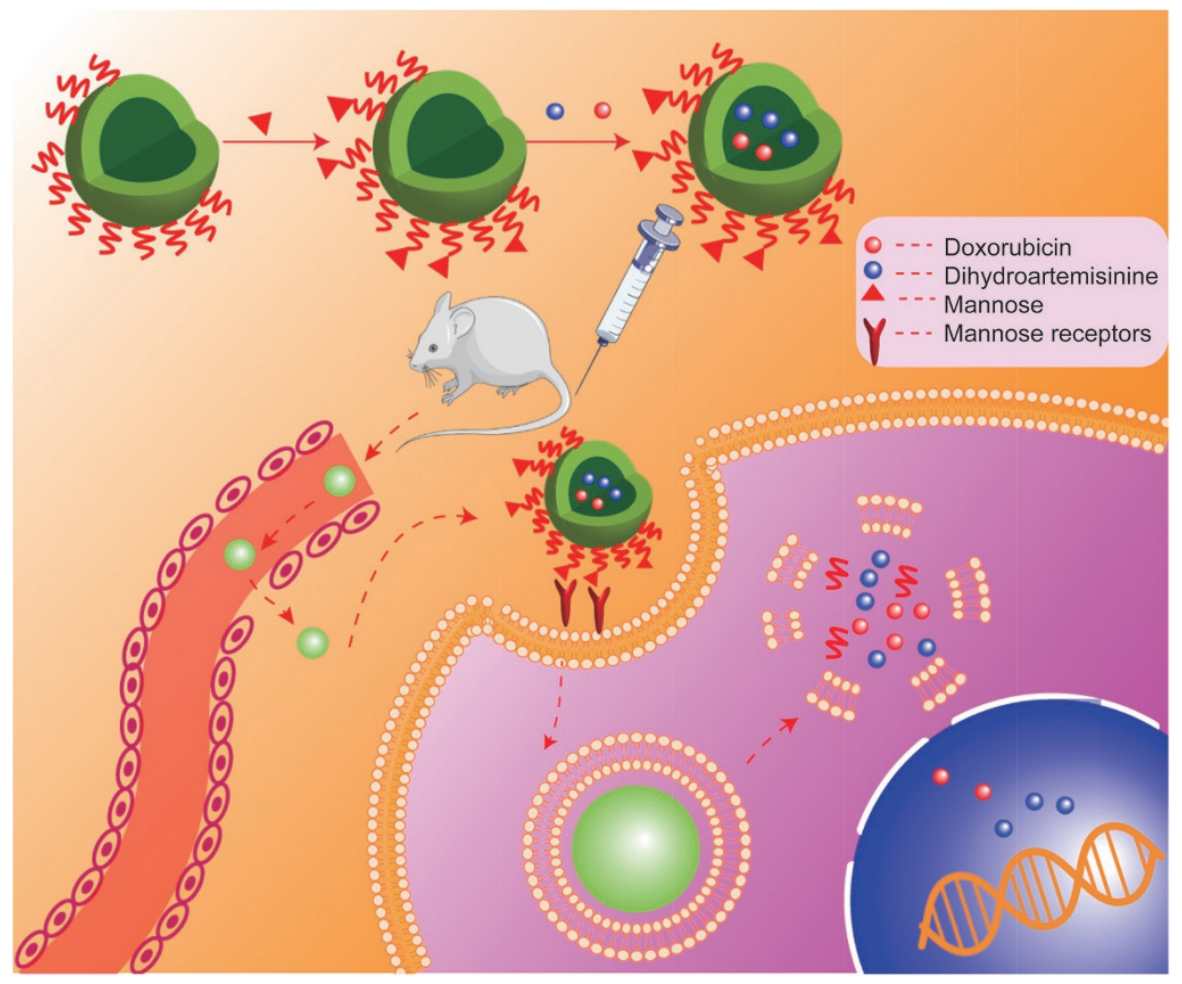

Figure 1. The mannose-modified liposomes for tumor targeted codelivery of Dox and DHA. 

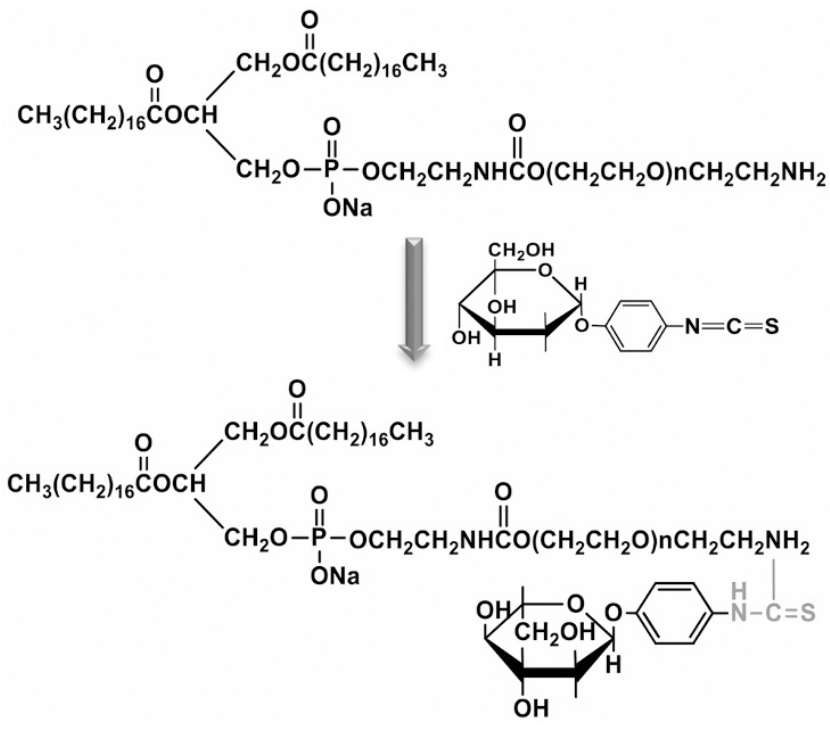

Figure 2. Illustration of synthetic DSPE-PEG $2000-$ Mannose. $^{2}$

were removed using a rotary evaporator in a $42^{\circ} \mathrm{C}$ water bath. The lipid film thus formed was hydrated with a $5 \%$ glucose solution. The suspensions were then extruded through a 200$\mathrm{nm}$ polycarbonate membrane with an extruder (Avanti Polar Lipids, Alabaster, USA). The un-encapsulated Dox and DHA were removed using a Sephadex G-50 column.

The particle size distribution and zeta potential of the liposomes were measured by a dynamic light scattering analyzer (Zetasizer Nano-90ZS, Malvern, UK). The transmission electronic microscopy (TEM) observations were conducted using a JEOL JEM-100CX2 TEM with an acceleration of $180 \mathrm{kV}$. The samples were pretreated with negative staining using uranyl acetate on a copper grid.

The Dox concentration was determined by a fluorometer ( $L_{\mathrm{ex}}=485 \mathrm{~nm}$ and $L_{\mathrm{em}}=590 \mathrm{~nm}$ ). The DHA concentration was measured using a UV spectrophotometric method. In brief, the DHA samples were dissolved in an assay solution composed of $2 \% \mathrm{NaOH}$ and ethanol $(4: 1, v / v)$, and incubated at $60^{\circ} \mathrm{C}$ for $30 \mathrm{~min}$. The absorbance was measured at $238 \mathrm{~nm}$. The drug loading coefficient (DL\%) and encapsulation efficiency $(\mathrm{EE} \%)$ of the liposomes were calculated by the equations:

$$
\mathrm{DL} \%=W_{\mathrm{DE}} / W_{\mathrm{L}} \times 100
$$

where $W_{\mathrm{DE}}$ was the drug amount encapsulated in liposomes and $W_{\mathrm{L}}$ was the total weight of liposomes and

$$
\mathrm{EE} \%=W_{\mathrm{DE}} / W_{\mathrm{T}} \times 100
$$

where $W_{\mathrm{DE}}$ was the drug amount encapsulated in liposomes and $W_{\mathrm{T}}$ was the total amount of drug added.

\section{In vitro stability of liposomes}

The stability of liposomes was evaluated for $12 \mathrm{~d}$ at $4^{\circ} \mathrm{C}$ by measuring changes in particle size and zeta potential.

\section{In vitro drug release assay of Man-liposomes}

The drug release in vitro was assayed using a dialysis method.
The Man-liposomes or the free drugs were placed in a dialysis bag (MWCO $14 \mathrm{kDa}$ ) and dialyzed in PBS (pH 7.4 or $\mathrm{pH} 5.6$ ) containing $0.5 \%$ Tween- 80 at $37^{\circ} \mathrm{C}$ on a shaker (110 rounds per minute). Drug concentrations were measured at various time points. Experiments were performed in triplicate.

In vitro cellular uptake and intracellular trafficking of Manliposomes

HCT8/ADR cells were seeded into 24-well plates at a density of $2 \times 10^{4}$ cells/well and cultured for $24 \mathrm{~h}$ before the test. The cells were treated with various samples, eg, free Dox, a combination of free Dox and DHA (free combo), liposomes, Manliposomes, and Man-liposomes pretreated with free mannose, at an equal Dox concentration of $5 \mu \mathrm{g} / \mathrm{mL}$ in fresh complete RPMI-1640 medium for $4 \mathrm{~h}$ at $37^{\circ} \mathrm{C}$. After replacement with fresh medium the cells were incubated for additional $4 \mathrm{~h}$. The cells were rinsed twice with cold PBS ( $\mathrm{pH} 7.4)$. The fluorescence images were photographed using a fluorescence microscope (Zeiss Axio Observer Z1). For flow cytometric analysis, the cells were harvested, rinsed twice with cold PBS ( $\mathrm{pH} 7.4$ ) and then subjected to flow cytometry (Beckman Coulter, USA). The data analysis was performed using FlowJo 7.6 software.

Observation by confocal laser scanning microscope (CLSM, Leica TCS SP8 STED) was further performed to investigate the intracellular distribution of Dox. A low Dox dose $(2.5 \mu \mathrm{g} / \mathrm{mL})$ was used for observation of its intracellular distribution while the cells remained considerable viability.

For evaluation of the competitive effects of mannose, the cells were pretreated with $1.5 \mathrm{mmol} / \mathrm{L}$ free mannose and then subjected to the regular procedures.

\section{Intracellular retention of Dox in HCT8/ADR cells}

HCT8/ADR cells at a density of $5 \times 10^{4}$ cells/well were seeded in 12-well plates and cultured for $24 \mathrm{~h}$. The cells were treated with various samples, eg, $10 \mu \mathrm{g} / \mathrm{mL}$ free Dox, $10 \mu \mathrm{g} / \mathrm{mL}$ Dox $+2 \mu \mathrm{g} / \mathrm{mL}$ DHA (free combo drugs), non-targeted liposomes, and Man-liposomes at the same concentrations as the combination of free drugs. After a 4-h incubation and replacement with fresh medium, the cells were cultured and collected at $0,0.5,1,2$, and $4 \mathrm{~h}$ time intervals. The collected cells were washed 3 times with PBS, and cell lysis was achieved by three freeze-thaw cycles. The supernatant was used to determine the intracellular Dox concentrations.

\section{Cytotoxicity study}

The in vitro cytotoxicities of free Dox, free DHA, free combo drugs, blank liposomes, liposomes and Man-liposomes were evaluated in the HCT8/ADR cell line using a standard MTT method. In brief, the cells were seeded into 96-well plates at a density of $6 \times 10^{3}$ cells/well and cultured for $24 \mathrm{~h}$. The cells were incubated with the drugs and liposome samples and then subjected to MTT assay. Cell viability was calculated according to:

$$
\text { Cell viability }(\%)=\left[\left(A_{\mathrm{T}}-A_{\mathrm{B}}\right) /\left(A_{\mathrm{u}}-A_{\mathrm{B}}\right)\right] \times 100
$$

where $A_{\mathrm{T}}, A_{\mathrm{u}}$, and $A_{\mathrm{B}}$ represented the absorbance of the tested groups, the untreated cells, and the blank culture medium, 
respectively.

\section{In vitro apoptosis assay and $\mathrm{Bcl}-\mathrm{xl}$ expression assayed by} Western blotting

The cells were incubated with free Dox $(0.05 \mu \mathrm{g} / \mathrm{mL})$, free combo drugs (Dox $0.05 \mu \mathrm{g} / \mathrm{mL}+$ DHA $2 \mu \mathrm{g} / \mathrm{mL}$ ), liposomes and Man-liposomes (with the same drug concentrations as the free combo drugs group) for $24 \mathrm{~h}$. The cells were then harvested, stained using an Annexin V-FITC Apoptosis Detection Kit in accordance with the manufacturer's protocol, and subjected to flow cytometry (Beckman Coulter, USA). The data analysis was performed using FlowJo 7.6 software.

In addition, the cells treated with the same combinations of drugs and liposomes were subjected to Western blot assays to examine the expression level of Bcl-xl.

\section{Tissue biodistribution studies}

The drug and liposome samples (free combo drugs, liposomes, Man-liposomes) were administered via tail vein at the same dose to the animals bearing subcutaneous HCT8/ADR tumors. At set time points, 1, 2, 6 and $12 \mathrm{~h}$ post-injection, the organs were dissected for ex vivo imaging on an IVIS ${ }^{\circledR}$ Spectrum system (Caliper, Hopkington, MA, USA). Dox fluorescence in the tissues was observed.

\section{In vivo antitumor study}

The therapeutic effect of Man-liposomes in comparison with that of free Dox $(1.5 \mathrm{mg} / \mathrm{kg} / 2 \mathrm{~d}$ ) and free combo drugs (Dox $1.5 \mathrm{mg} / \mathrm{kg} / 2 \mathrm{~d}+$ DHA $60 \mathrm{mg} / \mathrm{kg} / 2 \mathrm{~d}$ ) was investigated in the HCT8/ADR tumor model. When the tumor volume reached approximately $100 \mathrm{~mm}^{3}$, the mice were randomly grouped (5 mice per group) and treated with drugs by intravenous injection. The tumor size and body weight were recorded, and the tumor volume $(\mathrm{V})$ was calculated with the formula:

Tumor volume $\left(\mathrm{mm}^{3}\right)=($ long diameter $) \times(\text { short diameter })^{2} / 2$ At the end point of the experiment, the tumors and the major organs (heart, lung, spleen, kidney, and liver) were dissected for histological examination using hematoxylin and eosin (H\&E) staining. The immune histochemical staining of tumors was conducted with nuclear antigen Ki-67. Co-localization of Dox and cell nuclei in tumor tissues was observed by CLSM.

\section{Autophagy study}

The expression of cytosolic, microtubule-associated protein1A/1B-light chain 3 (LC3), an autophagy marker, was investigated using Western blotting analysis in HCT8/ADR cells treated with free Dox, free combo drugs and Man-liposomes for $24 \mathrm{~h}$. In brief, the cells were lysed, and the supernatant from the lysate was used for Western blotting. The proteins were separated at $120 \mathrm{~V}$ for $80 \mathrm{~min}$ on $15 \%$ PAGE-SDS gels and then transferred onto PVDF membranes (Millipore). The membranes were incubated with LC3B rabbit antibody (1:1000) overnight at $4{ }^{\circ} \mathrm{C}$, and after thorough washing, with goat anti-rabbit IgG-HRP antibody. Bands were detected using a ChemiDoc*MP imaging system. The expression of the MR and P-gp in the HCT8/ADR tumors or cells was also detected by this method.

\section{Statistical analysis}

Statistical analysis was performed using Origin 9.0. Statistical significance was evaluated using Student's $t$-test. Differences were considered significant at $P<0.05$.

\section{Results}

\section{Characterization}

The ${ }^{1} \mathrm{H}$ NMR spectrum showed characteristic signals of DSPE$\mathrm{PEG}_{2000}$-Man (Figure 3). The peaks at 7.0-7.5 ppm represented the phenyl group in MIPTC. The mannose modification rate of DSPE-PEG ${ }_{2000}$ was $88 \%$, and the Man-liposome formula (SPC/Chol/DSPE-PEG ${ }_{2000}$-Mannose) had an optimized molar ratio of 27:11:0.6.

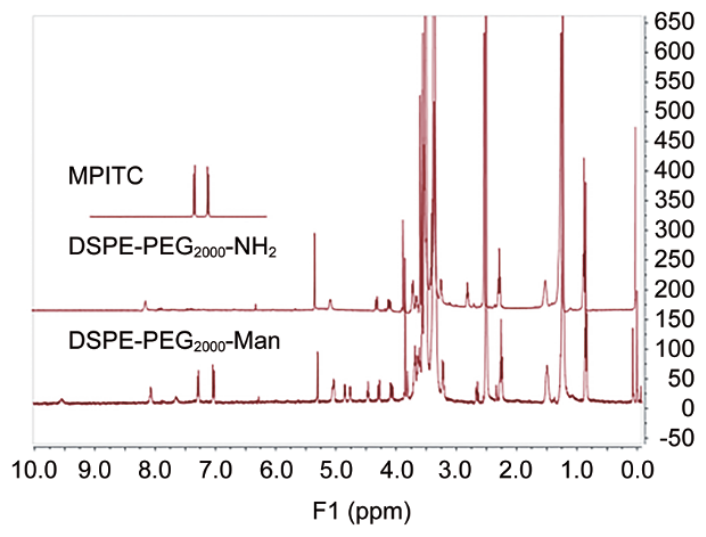

Figure 3. Characteristic ${ }^{1} \mathrm{H}$ NMR spectra.

The mean diameter and zeta potential of Man-liposomes were $158.8 \mathrm{~nm}$ (PDI 0.035) and $-15.8 \mathrm{mV}$, respectively (Figure $4 \mathrm{~A}$ and $4 \mathrm{~B}$ ). The TEM picture of Man-liposomes is shown in Figure 4C. The EE\% of the Man-liposomes and liposomes are listed in Table 1.

The stability of Man-liposomes remained consistent during a period of $12 \mathrm{~d}$, and the particle size and the zeta potential did not show obvious changes (Figure 4D).

\section{Drug release from Man-liposomes}

The Man-liposomes showed sustained release profiles. Interestingly, Dox release was $\mathrm{pH}$ dependent $(50.1 \%$ vs $78 \%$ at $72 \mathrm{~h}$, for $\mathrm{pH} 7.4$ and 5.6, respectively) (Figure 5). Hydrophobic

Table 1. Drug encapsulation efficiency, particle size, PDI, and zeta potential of liposomes.

\begin{tabular}{lcccc}
\hline & EE\% & $\begin{array}{c}\text { Particle size } \\
(\mathrm{nm})\end{array}$ & PDI & $\begin{array}{c}\text { Zeta potential } \\
(\mathrm{mV})\end{array}$ \\
\hline Blank liposomes & NA & 140.2 & 0.07 & - \\
Man-liposomes & 95.4 & 163.6 & 0.05 & -15.5 \\
Non-modified & 92.5 & 166.6 & 0.08 & -14.3 \\
\hline
\end{tabular}



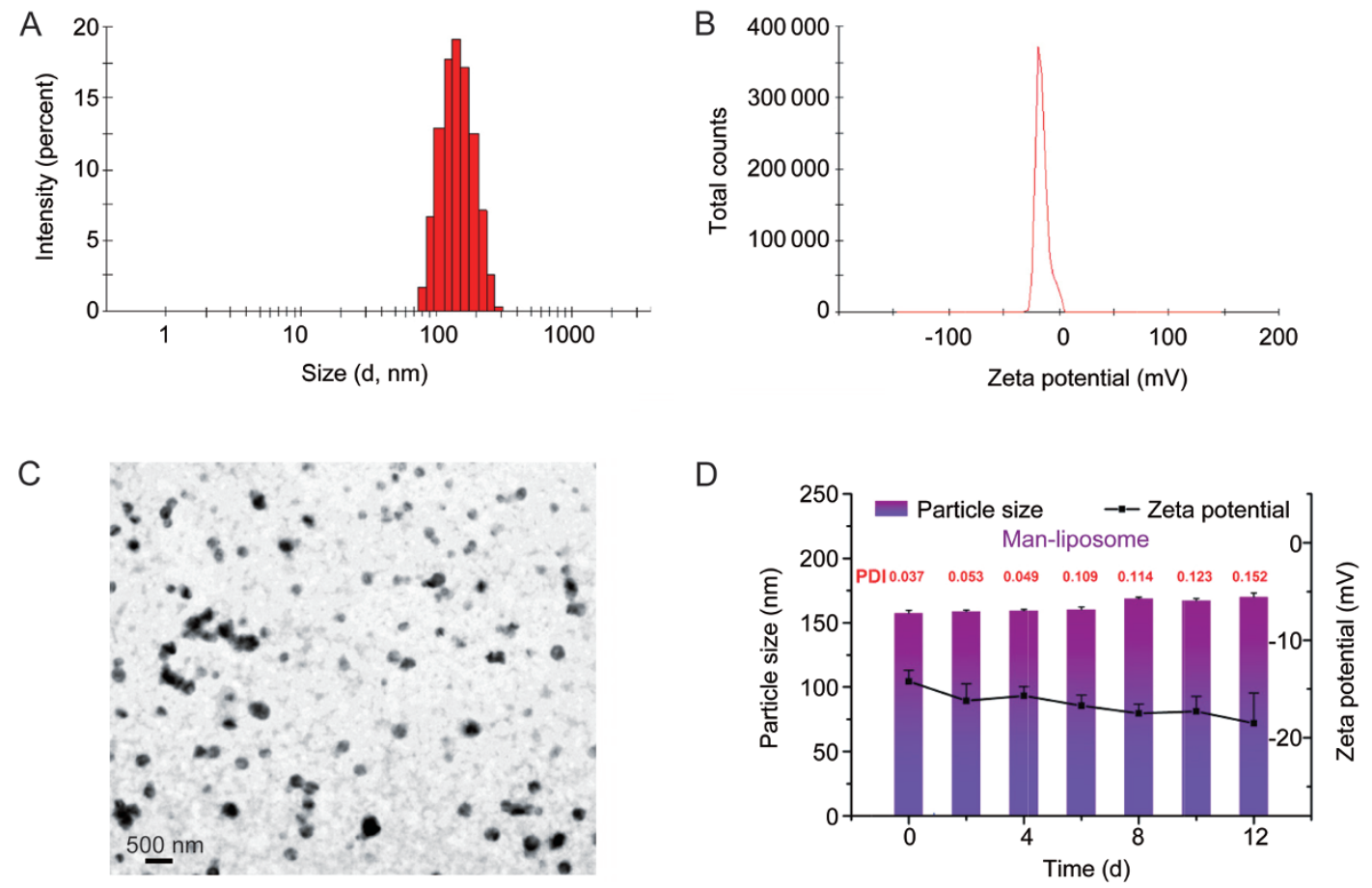

Figure 4. Characterizations of Man-liposomes. (A) Particle size. (B) Zeta potential. (C) Morphology of Man-liposomes by TEM. (D) Stability of Manliposomes in PBS (pH 7.4).

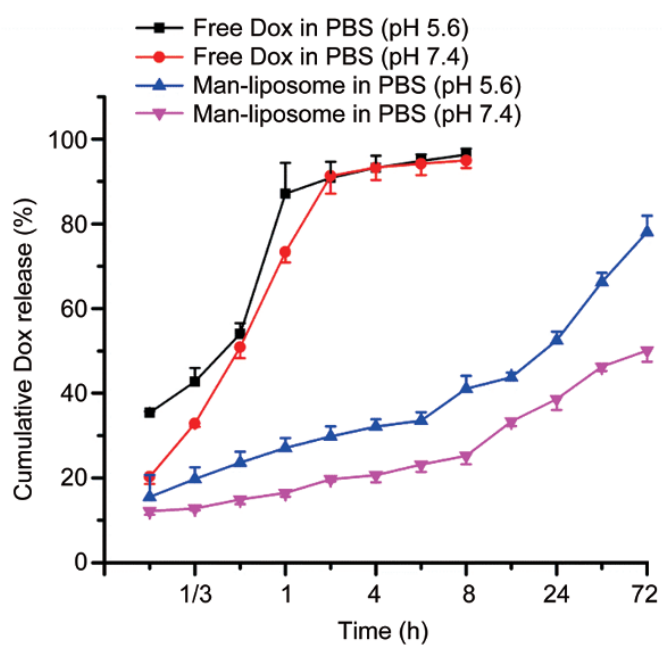

Figure 5. In vitro Dox release study of the Man-liposomes in PBS.

desalted Dox was used for preparation of the Man-liposomes with the advantage of its compatibility to be incorporated into the lipid bilayer. In addition, desalted Dox would dissolve rapidly upon entering an acidic environment because, it, with a $\mathrm{pKa} \leq 9.46$, is ionized readily at low $\mathrm{pH}$ while displaying slow release in the medium with neutral $\mathrm{pH}$. There is a 4-fold increase in solubility for desalted Dox in acidic buffers (1.1 and $4.5 \mu \mathrm{g} / \mathrm{mL}$ at $\mathrm{pH} 7.4$ and $\mathrm{pH} 5$, respectively $)^{[7]}$. Therefore, this property was advantageous to reduce the leakage of drugs in the blood but facilitate drug release in acidic organelles (eg, endosomes).

\section{Cell uptake and intracellular nucleolus trafficking of Man-} liposomes

As shown in Figure 6, the cellular uptake efficiency of Manliposomes in HCT8/ADR cells with MR overexpression was remarkably enhanced in comparison with free Dox and free combo drugs. If the cells were pretreated with free mannose, the uptake efficiency of the Man-liposomes was significantly decreased due to competitive binding to the MR. The results demonstrated the ability of MR-mediated intracellular delivery. Moreover, the presence of DHA slightly promoted the uptake of Dox into the HCT8/ADR cells.

The CLSM imaging further corroborated the results (Figure 6D). An interesting finding was that the Man-liposomes facilitated drug accumulation in cell nuclei, where Dox is active. This indicated that the Man-liposomes could alter the intracellular distribution of Dox, resulting in a higher concentration in the nuclei compared to the treatment with free Dox. Therefore, the drug concentration in the nuclei was enhanced, and treatment outcomes were improved.

\section{The retention of Dox with different forms in HCT8/ADR cells}

The Man-liposomes showed preferential nucleic accumulation, a property that could facilitate drug retention inside tumor cells. As shown in Figure 7, 42.41\%, 54.28\%, 60.54\%, and $76.79 \%$ of free Dox, free combo drugs, liposomes and Man-liposomes, respectively, remained inside the HCT8/ADR 
A
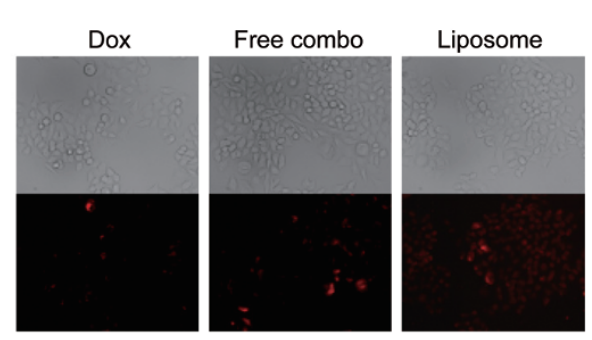

B

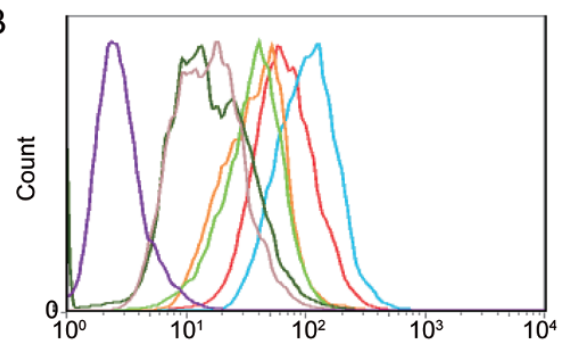

\begin{tabular}{|c|c|}
\hline SamplelD & Mean, FL3-H \\
\hline Blank & 3.33 \\
\hline Free Dox & 18.7 \\
\hline Free Combo & 21.6 \\
\hline Liposome & 43.2 \\
\hline Liposome + free mannose & 42.9 \\
\hline Man liposome & 120 \\
\hline Man liposome + free mannose & 77.5 \\
\hline
\end{tabular}

C

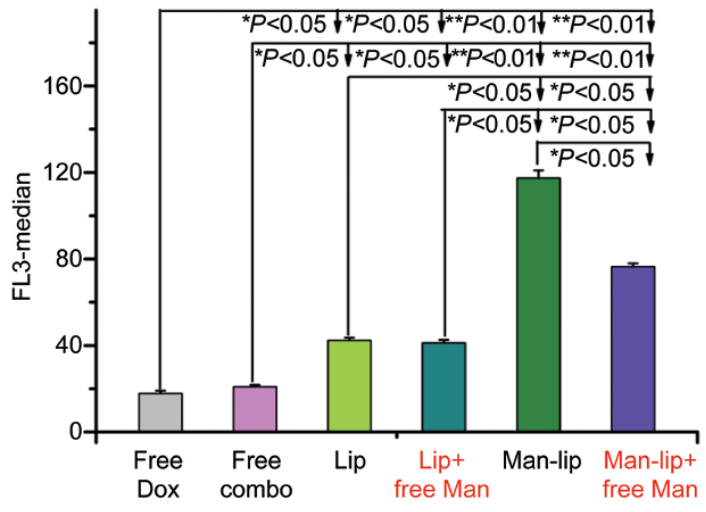

D
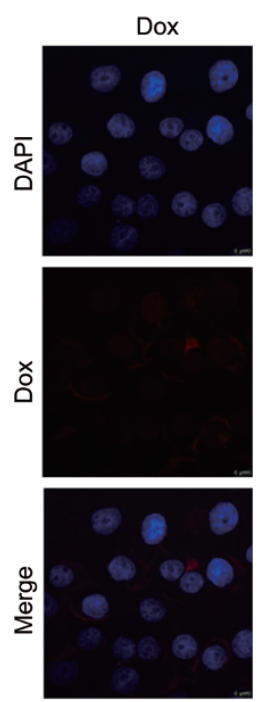

Free combo
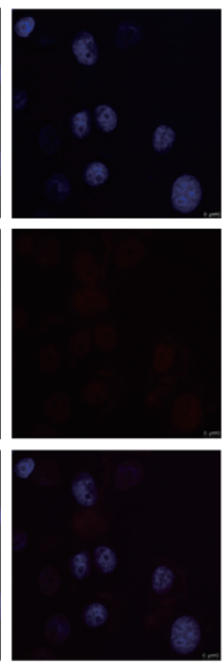

Liposome+ mannose
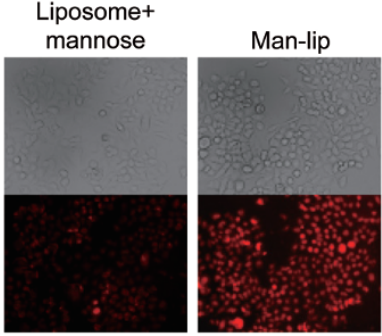

Man-lip+

mannose

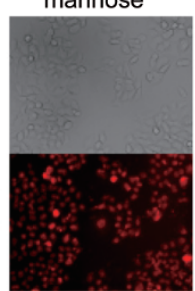

Figure 6. (A) Fluorescence microscope pictures of cellular uptake in HCT8/ADR cells. (B and C) Mean fluorescence intensity was determined by flow cytometry experiments. (D) Images from left to right show the fluorescence of DAPI and Dox and a merged image for five formulations. ${ }^{*} P<0.05$, ${ }^{* *} P<0.01$.

cells $4 \mathrm{~h}$ after the removal of the treatments. The area under the curve (AUC) was calculated in the plots of blood drug concentration vs time and was 461, 634, 1056 and $1517 \mathrm{ng} \cdot \mathrm{h} \cdot \mathrm{mL}^{-1}$ for the four groups above, respectively. This indicates that the enhanced intracellular bioavailability of the drug may be beneficial for overcoming drug resistance.
Cytotoxicity and apoptosis assays and inhibition of the Bcl-xI pathway

The MTT assay showed that the combo drugs showed a higher cytotoxicity than free Dox or DHA (Figure 8). The highest antitumor activity was seen in the Man-liposomes, of which the $\mathrm{IC}_{50}$ was $0.073 \mu \mathrm{g} / \mathrm{mL}$ while that of the liposomes was 

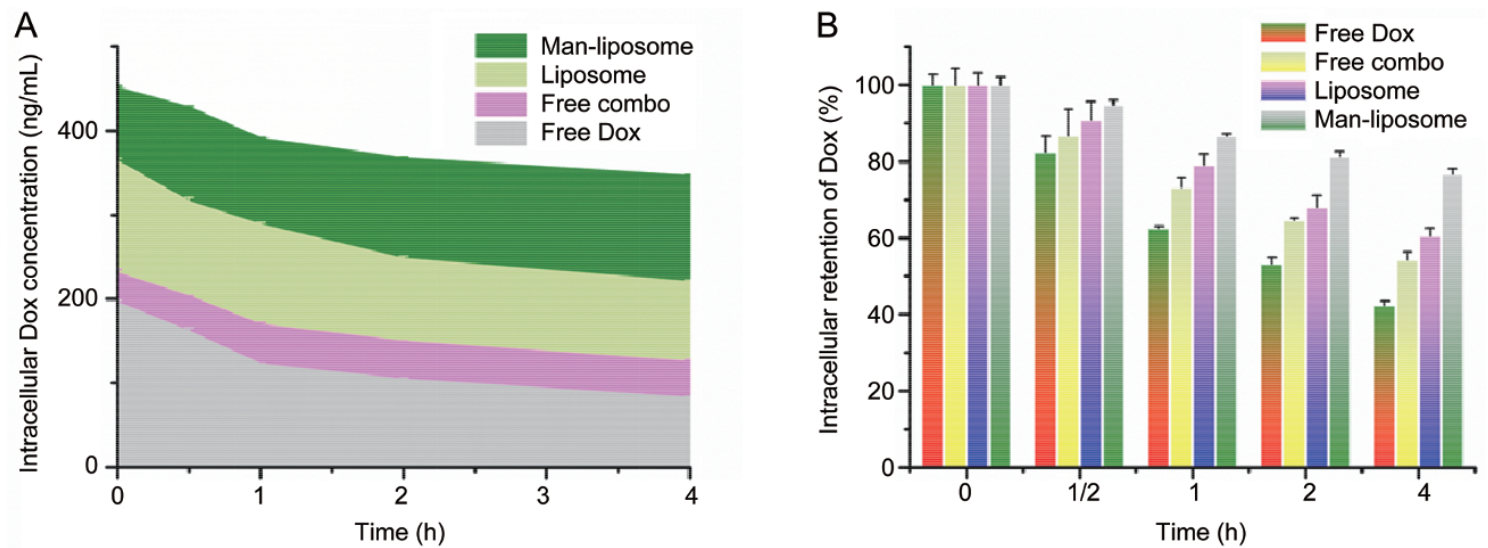

Figure 7. Resistance to drug efflux in HCT8/ADR cells. (A) Enhanced intracellular AUC with co-loaded liposomes. (B) Intracellular drug retention.
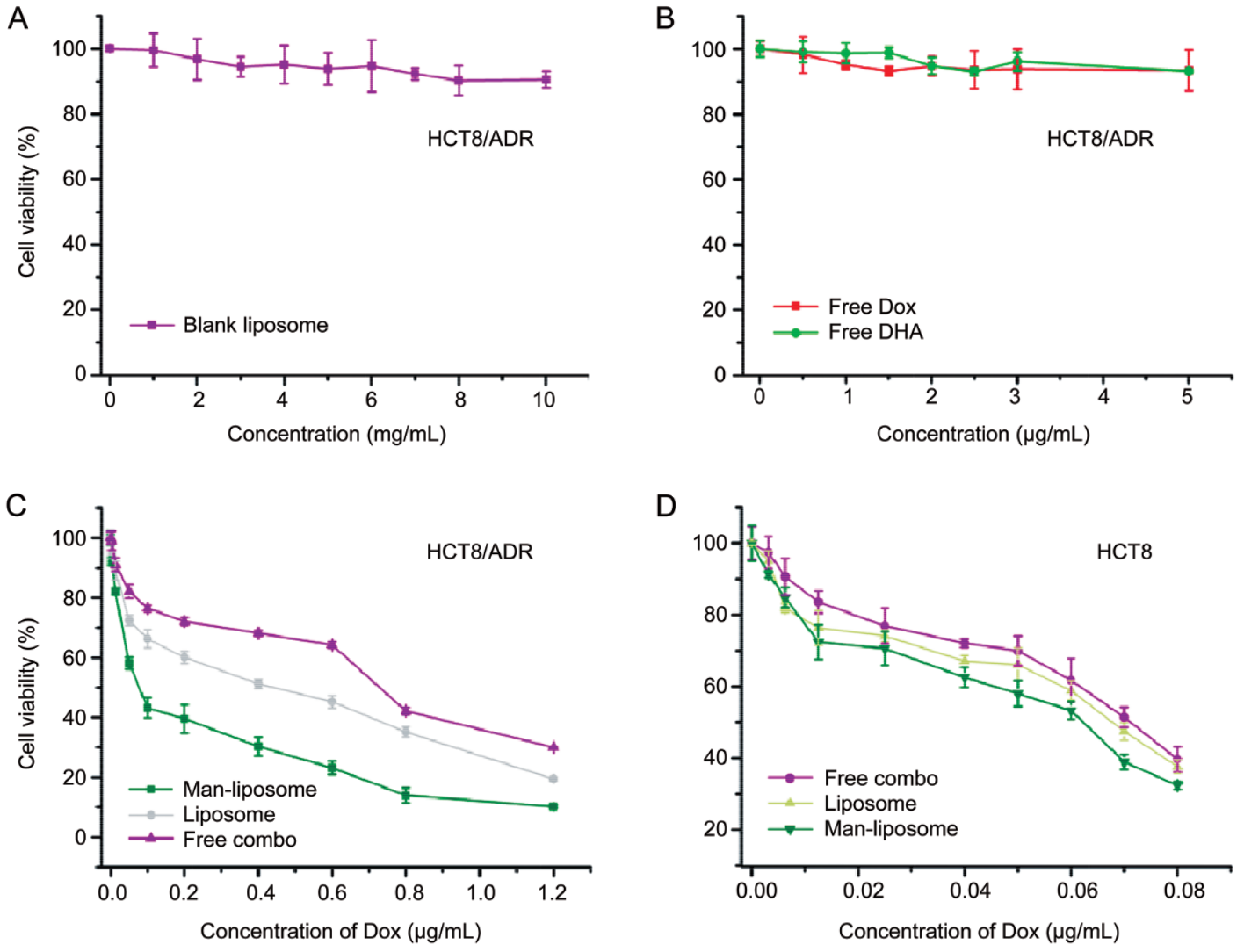

Figure 8. HCT8/ADR cytotoxicity after treatment with (A) blank liposomes, (B) free Dox, (C) free DHA or free Dox, and (D) free combo drugs, non-modified liposomes and the Man-liposomes.

$0.35 \mu \mathrm{g} / \mathrm{mL}$ and the free combo group $1.06 \mu \mathrm{g} / \mathrm{mL}$. Blank liposomes showed no apparent cytotoxicity, even when the lipid concentration reached $10 \mathrm{mg} / \mathrm{mL}$. Moreover, free Dox or DHA at the tested concentrations showed no antitumor activity on this cell line because of its MDR.

The apoptosis assay results exhibited a similar trend. The apoptotic rates were $7.2 \%, 11.6 \%, 18.4 \%$ and $50.5 \%$ for free
Dox, free combo drugs, liposomes and the Man-liposomes, respectively (Figure 9).

Bcl-xl is an anti-apoptotic protein, which is overexpressed in cancer and causes acquired chemoresistance ${ }^{[17]}$. The combo drug treatment efficiently down-regulated Bcl-xl, and treatment with the Man-liposomes showed the lowest level of Bcl-xl (Figure 9C). Therefore, down-regulation of Bcl-xl may 
A
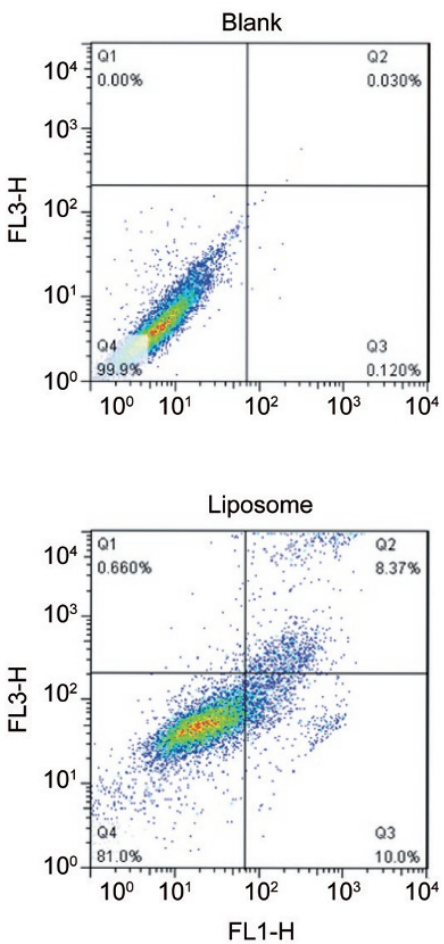
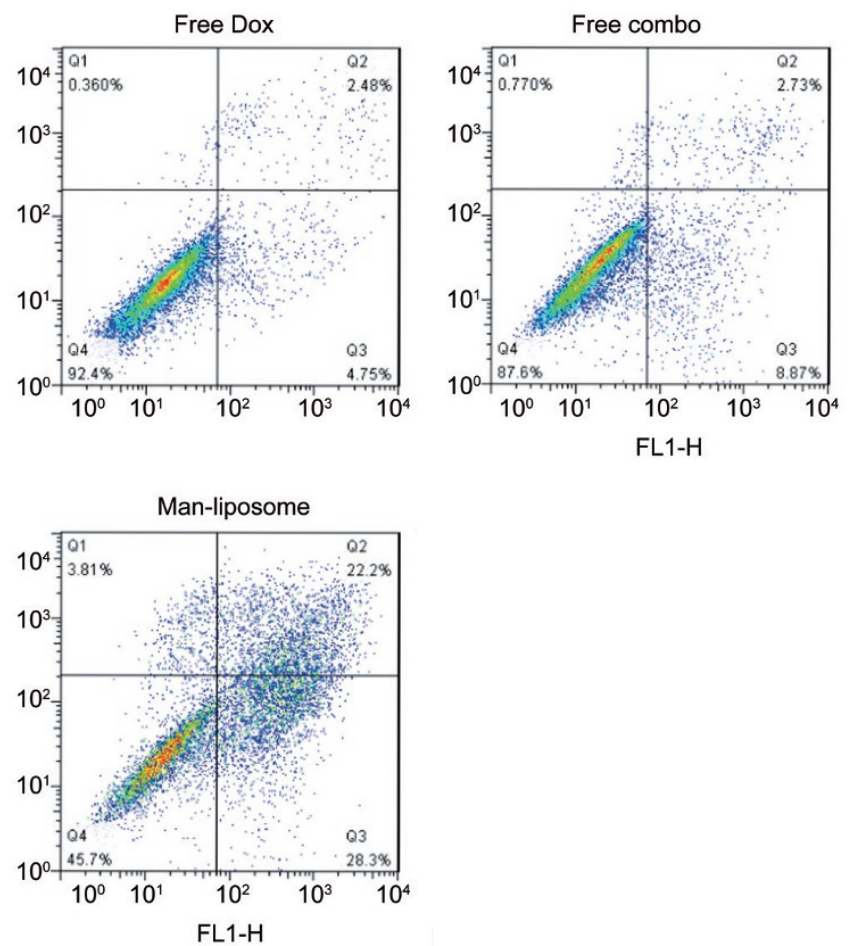

B

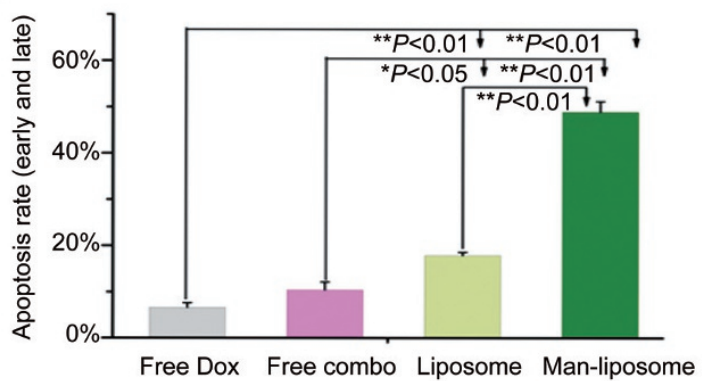

C

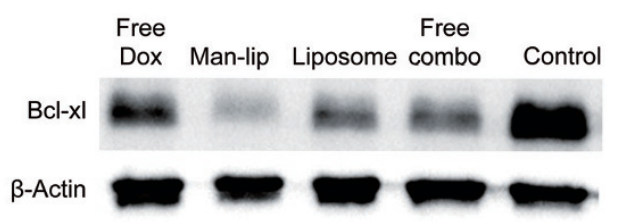

Figure 9. (A) Results of the apoptosis assay in HCT8/ADR cells after treatment with free Dox, free combo drugs, liposomes and Man-liposomes. (B) The apoptotic rates in the four treatment groups. (C) Western blot of Bcl-xl expression. ${ }^{*} P<0.05,{ }^{* * *} P<0.01$.

account for the anti-MDR effect seen in response to this combination therapy.

\section{Tissue biodistribution studies}

Non-specific accumulation of mannosylated carriers is a concern because of the high expression of the MR in the liver. At the pre-set time points, the organs were dissected for ex vivo imaging. The results showed no major difference in drug accumulation in the liver between these treatment groups. A large increase in the accumulation of Man-liposomes in tumors was observed (Figure 10A) and can be accounted for by the higher mannose receptor expression in tumors than in the liver (Figure 10B). Importantly, pro-tumor M2 phenotype macrophages overexpressed the MR, while the antitumor M1 macrophages had minor MR expression (data not shown). Therefore, the Man-liposomes could also potentially act on M2 macrophages and have an inhibitory effect.

\section{In vivo antitumor efficacy}

The in vivo therapy was conducted in a subcutaneous HCT8/ ADR tumor BALB/c nude mouse model. The results showed that tumor size in the mice receiving the Man-liposome treatment was the smallest among all the tested groups, represented by a tumor inhibition rate of $88.59 \%$, compared to $47.46 \%$ for free Dox and $70.54 \%$ for free combo drugs (Figure 11A-11C). The results demonstrated the effect of the Manliposomes on overcoming MDR.

The anti-MDR mechanism of the Man-liposomes could be accounted for by the enhanced tumor targeting effect mediated by the MR, which was overexpressed in the HCT8/ADR tumor tissues (Figure 11D). Moreover, the increased intranuclear delivery could also play an important role. As shown in Figure 12, remarkable co-localization of Dox and nuclei was found in the mice given the Man-liposomes, which indicated the benefit of improved intracellular distribution. 
A

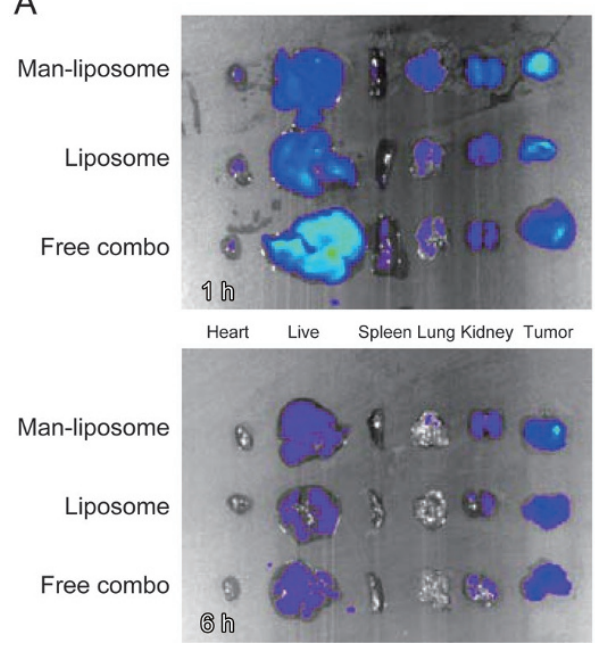

Epi-

fluorescence

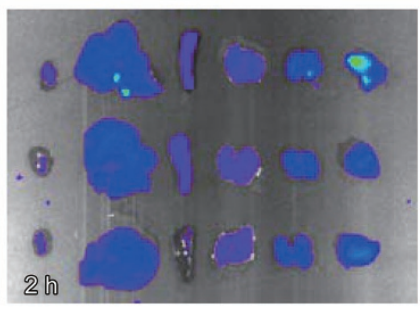

Heart Live Spleen Lung Kidney Tumor

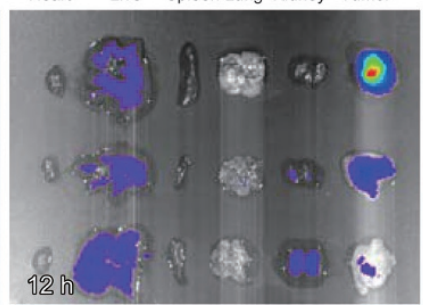

B

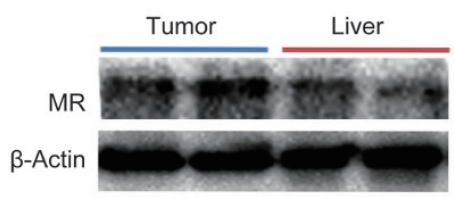

Figure 10. (A) Tissue biodistribution. (B) Western blot of MR expression.

A

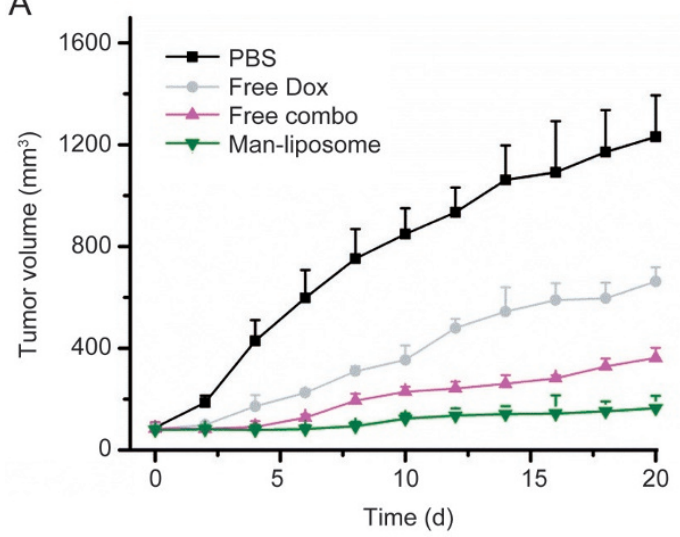

C

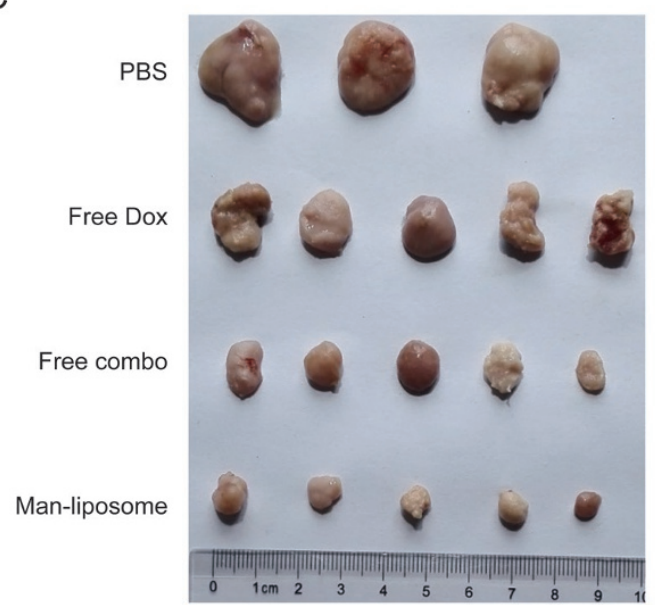

B

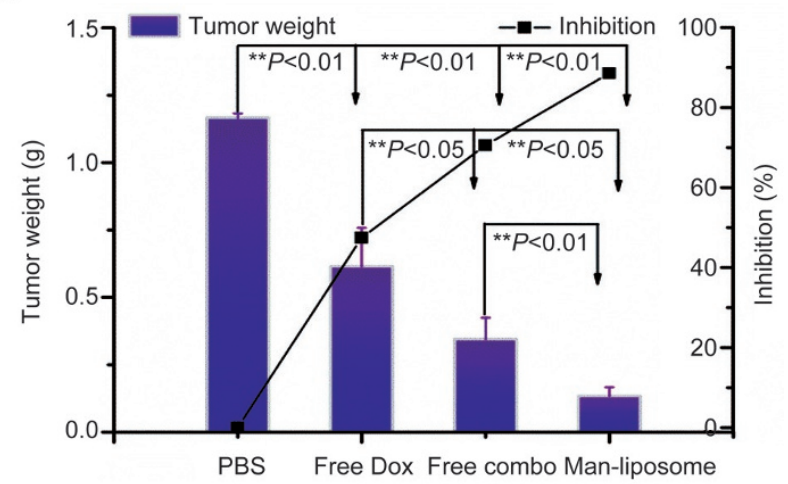

D

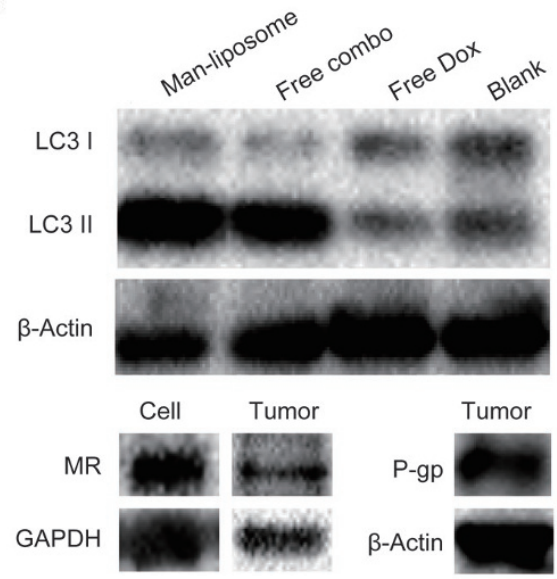

Figure 11. The anti-tumor effect on HCT8/ADR tumor bearing nude mice. (A) Tumor volume growth curves. (B) The weights of tumors at the end of different treatments. (C) The photographs of tumors at the end of different treatments. (D) The MR, P-gp expression on HCT8/ADR tumors and cells, and the expression of LC3 of HCT8/ADR cells after different treatments. ${ }^{*} P<0.05,{ }^{* *} P<0.01$. 

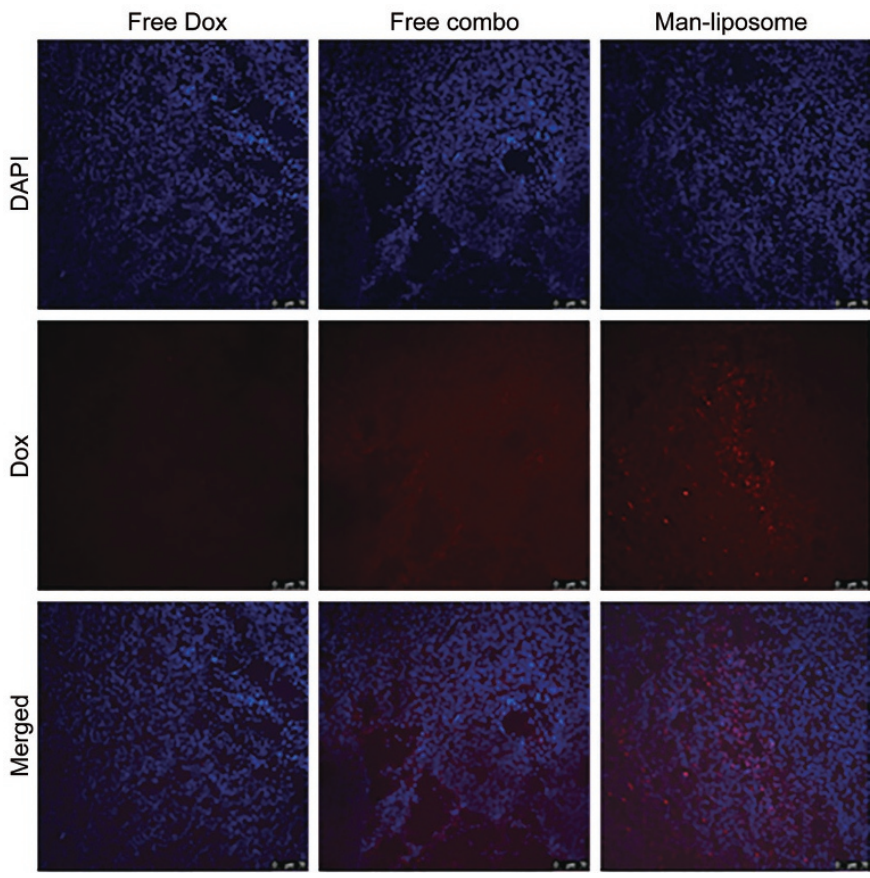

Figure 12. The co-localization of Dox and DAPI on tumor tissues.

It has been reported that DHA can work synergistically with chemotherapeutics by inducing autophagy ${ }^{[18]}$. Our results also revealed enhanced autophagy induced by Man-liposomes, as reflected by the increased ratio of LC3-II/LC3-I (Figure 11D). LC3-II is a lipidated form of LC3-I and is attached to both the phagophore and the autophagosome membrane. The ratio of LC3-II/LC3-I is a biochemical marker for autophagosome formation $^{[19]}$. The results suggested that induction of autophagy could be an important anti-MDR mechanism for the Manliposomes.

The biocompatibility of the Man-liposomes was evaluated. The body weight of mice in the free Dox treatment group decreased, but no major changes were seen in the other treatment groups (Figure 13A). Higher organ coefficients were seen in the Man-liposome group than in the other treatment groups, but the difference was not necessarily related to side toxicity (Figure 13B). For example, although the liver coefficient was highest in the Man-liposome group, there was no obvious increase in liver accumulation in the Man-liposome group, as shown in Figure 10A. Moreover, the histological results showed that the animals in the PBS, free Dox, and free combo treatment groups had liver lesions which could lead to the decrease of the liver organ coefficient in these groups.

Furthermore, the histological examination also revealed that the heart, lungs, and spleen tissues of mice treated with the Man-liposomes were similar to those of mice in the PBS treatment group and no pathological changes were observed (Figure 13C). However, the free Dox group showed multiple types of hepatic damage; for instance, the hepatic sinusoid around the lesions was expanded, focal inflammatory cells aggregated in the portal area, and multi-focal necrosis or apoptosis were seen.

The proliferation marker Ki-67 is often used to assess growth. Apoptosis in colon cancers is associated with proliferative activity that can be assessed by Ki-67 labeling ${ }^{[20]}$. As shown in Figure 13C (right panel), the Ki-67-positive fraction (red arrow) in the Man-liposomes group was significantly reduced compared with that in the other treatment groups, indicating the inhibition of tumor growth and induction of apoptosis.

\section{Discussion}

MDR is a major hurdle in chemotherapy. Chinese medicine as adjuvant therapy combined with chemotherapy has long been used clinically in China ${ }^{[21,22]}$. Active compounds, sourced from Chinese medicine, show synergistic effects with chemotherapeutic drugs ${ }^{[23]}$. Some of them have been studied in clinical trials (eg, andrographolides for colorectal cancer treatment, ClinicalTrials.gov Identifier: NCT01993472; and artesunate for metastatic breast cancer, NCT00764036).

DHA kills cancer cells through various mechanisms, such as the induction of apoptosis ${ }^{[24]}$, generation of active oxygen radi$\operatorname{cals}^{[25]}$, ferroptosis ${ }^{[26]}$, cell cycle arrest and inhibition of nuclear factor- $\mathrm{KB}^{[27]}$. Our results revealed that DHA can re-sensitize HCT8/ADR tumor cells to Dox, and the two drugs work synergistically on drug-resistant colon cancer. The MDR reversal mechanisms could involve the preferential nuclear accumulation of the drugs, enhanced apoptosis, and the induction of autophagy. Of note, the drug combination resulted in downregulation of Bcl-xl. Because Bcl-xl is an important signal in a pathway associated with chemoresistance, suppression of Bcl-xl plays a key role in anti-MDR. Nevertheless, more details still need to be determined with further investigations.

Autophagy activation is favorable for the survival of the resistant phenotype of cancer cells during chemotherapy, and autophagy inhibitors can resensitize the chemoresistant cells, thus driving the apoptosis-defective cancer cells toward death $^{[28]}$. However, autophagy can be a death executor and reverse drug resistance upon its activation by enhanced induction of apoptosis and necrosis ${ }^{[2]}$. Therefore, autophagy induction could serve as a new tool for anti-MDR.

It was an interesting finding that the drug-resistant colon cancer cells (HCT8/ADR) overexpressed the MR. The MR is also responsible for the transportation of glucose, an essential energy source for metabolically active cancer cells. Nutrient transporters have been demonstrated to have a promising application in biomimetic delivery ${ }^{[30]}$. Nano drug carriers are often modified with nutrient compounds that target the tumor cells that overexpress nutrient transporters, thus serving as transport portals and facilitating receptor-mediated intracellular delivery. Our data showed that the mannosylated liposomes greatly enhanced the intracellular delivery of Dox and DHA, yielding improved nuclear distribution and in vivo treatment outcomes.

\section{Conclusion}

In this study, DHA was used in combination with Dox for 

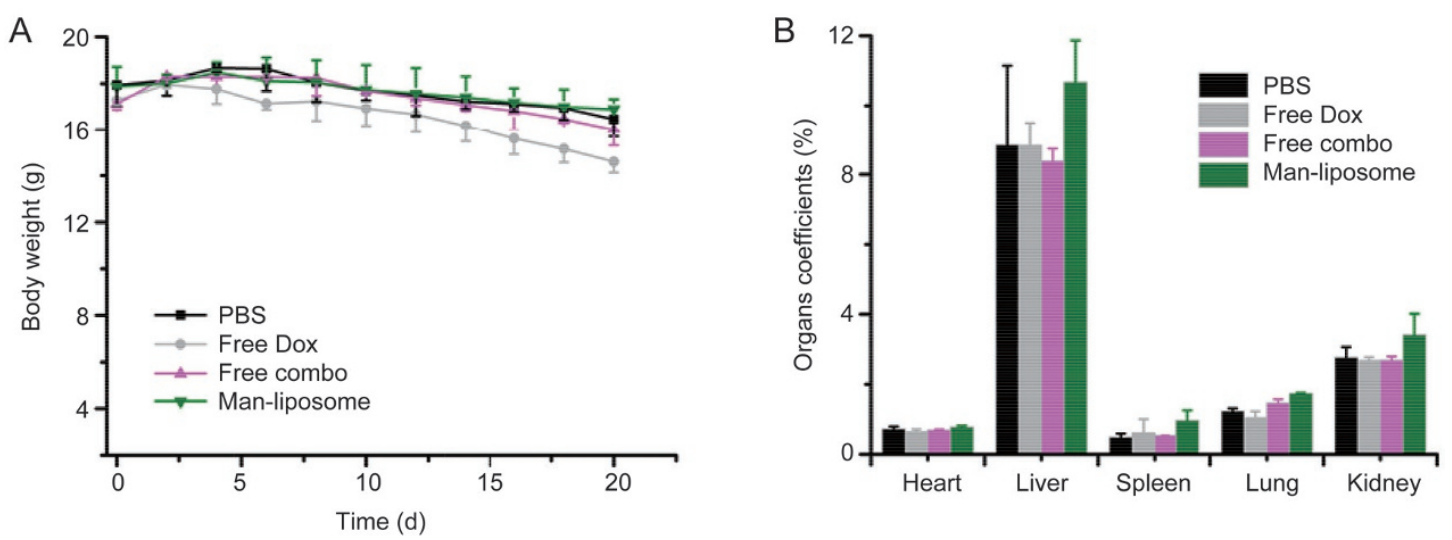

C
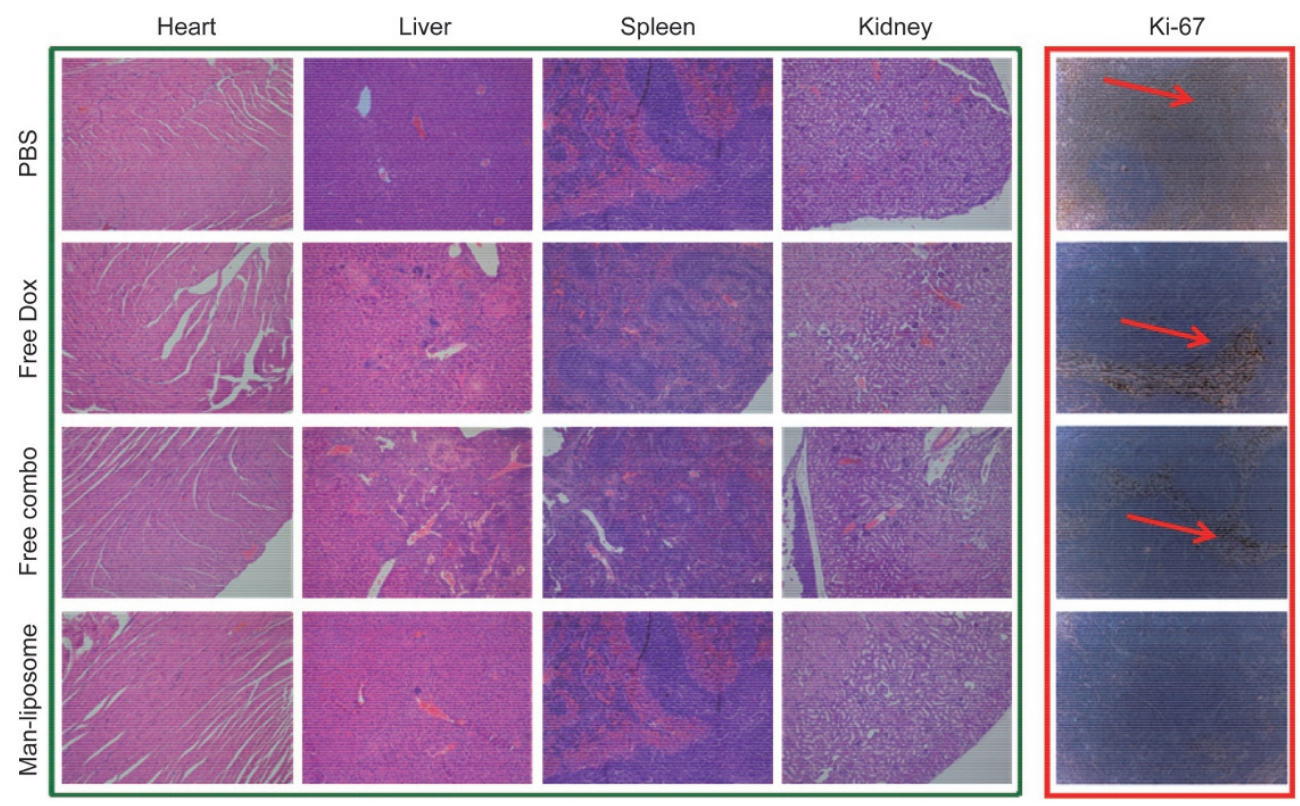

Figure 13. (A) The changes in body weight under various treatments. (B) The organ coefficients of mice. (C) H\&E analysis of major organs after treatments and cellular proliferation by immune histochemical staining with the Ki-67 agent.

anti-MDR colon therapy. The combination was able to inhibit the growth of the drug-resistant colon cancer cells, yielding a remarkable synergistic effect. A tumor-targeted system was developed for codelivery of the two drugs. DHA and Dox were co-encapsulated into the mannosylated liposomes for targeted delivery to cancer cells overexpressing the mannose receptor. Preferential nuclear accumulation of the drugs, enhanced apoptosis, downregulation of Bcl-xl, and induction of autophagy were all associated with reversing MDR. A codelivery strategy and combination drug therapy provide a potential method for anti-MDR colon cancer therapy.

\section{Acknowledgements}

This work was supported by the 973 Program, China (2014CB931900 and 2013CB932503) and the National Natural Science Foundation of China (81373357, 81422048, 81402883, 81521005 , and 81673382 ). It was also partially supported by the Scientific Research and Equipment Development Project,
Chinese Academy of Sciences (YZ201437).

\section{References}

1 Arnold M, Sierra MS, Laversanne M, Soerjomataram I, Jemal A, Bray F. Global patterns and trends in colorectal cancer incidence and mortality. Gut 2016; pii: gutjnl-2015-310912.

2 Chen W, Zheng R, Zuo T, Zeng H, Zhang S, He J. National cancer incidence and mortality in China, 2012. Chin J Cancer Res 2016; 28 : $1-11$.

3 Ferlay J, Soerjomataram I, Dikshit R, Eser S, Mathers C, Rebelo M, et al. Cancer incidence and mortality worldwide: sources, methods and major patterns in GLOBOCAN 2012. Int J Cancer 2015; 136: E35986.

$4 \mathrm{Hu} \mathrm{T}$, Li Z, Gao CY, Cho CH. Mechanisms of drug resistance in colon cancer and its therapeutic strategies. World J Gastroenterol 2016; 22: 6876-89.

5 Vredenburg MR, Ojima I, Veith J, Pera P, Kee K, Cabral F, et al. Effects of orally active taxanes on P-Glycoprotein modulation and colon and breast carcinoma drug resistance. J Natl Cancer Inst 2001; 93 : 
1234-45.

6 Herzog CE, Trepel JB, Mickley LA, Bates SE, Fojo AT. Various methods of analysis of mdr-1/P-glycoprotein in human colon cancer cell lines. J Natl Cancer Inst 1992; 84: 711-6.

7 Wang $\mathrm{H}$, Zhao Y, Wang $\mathrm{H}$, Gong J, He H, Shin MC, et al. Low-molecularweight protamine-modified PLGA nanoparticles for overcoming drugresistant breast cancer. J Control Release 2014; 192: 47-56.

8 Liu J, Zhao Y, Guo Q, Wang Z, Wang H, Yang Y, et al. TAT-modified nanosilver for combating multidrug-resistant cance. Biomaterials 2012; 33: 6155-61.

9 Longley DB, Johnston PG. Molecular mechanisms of drug resistance. J Pathol 2005; 205: 275-92.

10 Bozic I, Reiter JG, Allen B, Antal T, Chatterjee K, Shah P, et al. Evolutionary dynamics of cancer in response to targeted combination therapy. eLife 2013; 2: e00747.

11 Wang P, Yang HL, Yang YJ, Wang L, Lee SC. Overcome cancer cell drug resistance using natural products. Evid Based Complement Alternat Med 2015; 2015: 767136.

12 Wang S, Wang H, Liang W, Huang Y. An injectable hybrid nanoparticlein-oil-in-water submicron emulsion for improved delivery of poorly soluble drugs. Nanoscale Res Lett 2012; 7: 219.

13 Lai HC, Singh NP, Sasaki T. Development of artemisinin compounds for cancer treatment. Invest New Drugs 2013; 31: 230-46.

14 Wu GS, Lu JJ, Guo JJ, Huang MQ, Gan L, Chen XP, et al. Synergistic anti-cancer activity of the combination of dihydroartemisinin and doxorubicin in breast cancer cells. Pharmacol Rep 2013; 65: 453-9.

15 Feng $\mathrm{X}$, Li L, Jiang $\mathrm{H}$, Jiang $\mathrm{K}$, Jin $\mathrm{Y}$, Zheng J. Dihydroartemisinin potentiates the anticancer effect of cisplatin via mTOR inhibition in cisplatin-resistant ovarian cancer cells: involvement of apoptosis and autophagy. Biochem Biophys Res Commun 2014; 444: 376-81.

16 Hayashi N, Kataoka H, Yano S, Tanaka M, Moriwaki K, Akashi H, et al. A novel photodynamic therapy targeting cancer cells and tumorassociated macrophages. Mol Cancer Ther 2015; 14: 452.

17 Al-Harbi S, Choudhary GS, Ebron JS, Hill BT, Vivekanathan N, Ting AH, et al. miR-377-dependent $\mathrm{BCL}-\mathrm{xL}$ regulation drives chemotherapeutic resistance in B-cell lymphoid malignancies. Mol Cancer 2015; 14 : 185.

18 Zhang ZS, Wang J, Shen YB, Guo CC, Sai KE, Chen FR, et al. Dihydroartemisinin increases temozolomide efficacy in glioma cells by inducing autophagy. Oncol Lett 2015; 10: 379-83.

19 Tanida I, Ueno T, Kominami E. LC3 and autophagy. Methods Mol Biol 2008; 445: 77-88.

20 Takano Y, Saegusa M, Ikenaga M, Mitomi H, Okayasu I. Apoptosis of colon cancer: comparison with Ki-67 proliferative activity and expression of p53. J Cancer Res Clin Oncol 1996; 122: 166-70.

21 Li SG, Chen HY, Ou-Yang CS, Wang XX, Yang ZJ, Tong Y, et al. The efficacy of Chinese herbal medicine as an adjunctive therapy for advanced non-small cell lung cancer: a systematic review and metaanalysis. PLoS One 2013; 8: e57604.

22 Qi F, Zhao L, Zhou A, Zhang B, Li A, Wang Z, et al. The advantages of using traditional Chinese medicine as an adjunctive therapy in the whole course of cancer treatment instead of only terminal stage of cancer. Biosci Trends 2015; 9: 16-34.

23 Li C, Sun BQ, Gai XD. Compounds from Chinese herbal medicines as reversal agents for P-glycoprotein-mediated multidrug resistance in tumours. Clin Transl Oncol 2014; 16: 593-8.

$24 \mathrm{Hu} \mathrm{CJ}$, Zhou L, Cai Y. Dihydroartemisinin induces apoptosis of cervical cancer cells via upregulation of RKIP and downregulation of Bcl-2. Cancer Biol Ther 2014; 15: 279-88.

25 Ontikatze T, Rudner J, Handrick R, Belka C, Jendrossek V. Dihydroartemisinin is a hypoxia-active anti-cancer drug in colorectal carcinoma cells. Front Oncol 2014; 4: 116.

26 Lin R, Zhang Z, Chen L, Zhou Y, Zou P, Feng C, et al. Dihydroartemisinin (DHA) induces ferroptosis and causes cell cycle arrest in head and neck carcinoma cells. Cancer Lett 2016; 381: 165-75.

27 Chen H, Sun B, Wang S, Pan S, Gao Y, Bai X, et al. Growth inhibitory effects of dihydroartemisinin on pancreatic cancer cells: involvement of cell cycle arrest and inactivation of nuclear factor-kappaB. J Cancer Res Clin Oncol 2010; 136: 897-903.

28 Amaravadi RK, Lippincott-Schwartz J, Yin XM, Weiss WA, Takebe $\mathrm{N}$, Timmer W, et al. Principles and current strategies for targeting autophagy for cancer treatment. Clin Cancer Res 2011; 17: 654-66.

29 Panzarini E, Dini L. Nanomaterial-induced autophagy: a new reversal MDR tool in cancer therapy? Mol Pharm 2014; 11: 2527-38.

30 Geldenhuys WJ, Mohammad AS, Adkins CE, Lockman PR. Molecular determinants of blood-brain barrier permeation. Ther Deliv 2015; 6: 961-71. 